\title{
Endovascular Therapy for Ischemic Stroke
}

\author{
Ramana M R Appireddy, ${ }^{a}$ Andrew M Demchuk, ${ }^{b}$ Mayank Goyal, ${ }^{c}$ \\ Bijoy K Menon, ${ }^{d}$ Muneer Eesa, ${ }^{e}$ Philip Choi, ${ }^{f}$ Michael D. Hill ${ }^{g}$ \\ ${ }^{a}$ Department of Clinical Neurosciences, Faculty of Medicine, University of Calgary, Calgary, AB, Canada \\ ${ }^{b}$ Departments of Clinical Neurosciences and Radiology, Hotchkiss Brain Institute, Faculty of Medicine, \\ University of Calgary, Calgary, AB, Canada \\ 'Departments of Clinical Neurosciences and Radiology, Faculty of Medicine, University of Calgary, Calgary, AB, Canada \\ 'Department of Clinical Neurosciences, Hotchkiss Brain Institute, Faculty of Medicine, University of Calgary, Calgary, AB, Canada

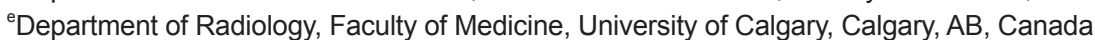 \\ 'Department of Clinical Neurosciences, Faculty of Medicine, University of Calgary, Calgary, AB, Canada \\ ${ }^{9}$ Departments of Clinical Neurosciences, Medicine, Radiology, and Community Health Sciences, \\ Hotchkiss Brain Institute, Faculty of Medicine, University of Calgary, Calgary, AB, Canada
}

Received September 2, 2014

Revised October 23, 2014

Accepted October 23, 2014

\section{Correspondence}

Michael D. Hill, MD, MSc, FRCPC

Calgary Stroke Program,

Department of Clinical

Neurosciences,

Hotchkiss Brain Institute,

Foothills Hospital,

University of Calgary,

Rm 1242A, 1403 29th Street NW,

Calgary, AB T2N 2T9, Canada

Tel +14039448065

Fax +14032832270

E-mail michael.hill@ucalgary.ca
The utility of intravenous tissue plasminogen activator (IV t-PA) in improving the clinical outcomes after acute ischemic stroke has been well demonstrated in past clinical trials. Though multiple initial small series of endovascular stroke therapy had shown good outcomes as compared to IV t-PA, a similar beneficial effect had not been translated in multiple randomized clinical trials of endovascular stroke therapy. Over the same time, there have been parallel advances in imaging technology and better understanding and utility of the imaging in therapy of acute stroke. In this review, we will discuss the evolution of endovascular stroke therapy followed by a discussion of the key factors that have to be considered during endovascular stroke therapy and directions for future endovascular stroke trials.

J Clin Neurol 2015;11(1):1-8

Key Words endovascular therapy, stroke, mechanical thrombectomy.

\section{Introduction}

Ischemic stroke occurs due to interruption of the blood supply to the brain. The hypoperfused brain at risk of infarction has two distinct regions, penumbra and core or umbra. ${ }^{1}$ Penumbra is the area of the hypoperfused brain supplied by the collateral circulation that is still viable but at risk of irreversible infarction if blood flow is not restored. The core is the region of hypoperfused brain which is already infarcted. ${ }^{2}$ The introduction of intravenous tissue plasminogen activator (IV t-PA) as a successful therapy for acute ischemic stroke was a milestone

(a) This is an Open Access article distributed under the terms of the Creative Commons Attribution Non-Commercial License (http://creativecommons.org/licenses/by-nc/3.0) which permits unrestricted non-commercial use, distribution, and reproduction in any medium, provided the original work is properly cited. in the field of medicine and along with the technological developments in the field of neuroimaging and angiography has further opened up avenues for development of novel technologies for acute stroke care. ${ }^{3}$ Modern endovascular stroke therapy is a result of these advances and is the main focus of this review.

Thrombolysis, the mainstay of acute therapy, can be achieved by pharmacological, mechanical or a mixture of both methods. The thrombus consists of a variable mixture of fibrin strands with platelets and red blood cells. The exact composition of the thrombus depends on its source and hemodynamics in the vessel during the thrombus formation. ${ }^{4}$ Innate thrombolytic mechanisms include chemical thrombolysis mediated by plasmin. Arterial blood flow helps in augmenting this process by the mechanical disruption of the thrombus. Tissue plasminogen activator (t-PA) acts by hydrolyzing plasminogen to plas- 
min, which in turns dissolves the thrombus leading to restoration of the blood flow. However the utility and efficacy of IV t-PA in acute stroke therapy is limited by a narrow time window for treatment, thrombus burden, thrombus composition, and patient related thrombolytic contraindications. ${ }^{5,6}$ Site of occlusion is a major factor with rates of recanalization dropping dramatically with proximal occlusions. The rates of recanalization with distal middle cerebral arteries is $44 \%$ versus $25-29 \%$ with proximal middle cerebral arteries and $10 \%$ with terminal internal carotid arteries. ${ }^{7-9}$ Thrombolysis using IV t-PA is only effective in improving outcomes in a minority of patients.

\section{Endovascular Stroke Treatment - The Adventures and Disappointments}

The earliest attempts at intra arterial thrombolysis were reported by Sussman in 1958 using purified plasmin (Fibrinoly$\left.\sin ^{\mathrm{TM}}\right) .{ }^{10}$ Over the next few decades, the development and improved understanding of thrombolytic drugs, advances in the neuroimaging and angiographic equipment led to the active resurgence of endovascular stroke therapy with several small case series and pilot studies in the late 80's and early 90's culminating in the era of prospective randomized endovascular stroke trials. ${ }^{11-21}$ In 1996, FDA approved the use of t-PA for intravenous use within 3 hours of stroke onset based upon the result of National Institute of Neurological Disorders and Stroke t-PA study. ${ }^{3}$ Prolyse in Acute Cerebral Thromboembolism Trial II (PROACT) was the first prospective randomized trial looking at safety and efficacy of intra-arterial (IA) recombinant prourokinase (r-proUK) and heparin vs. saline placebo and heparin. PROACT-II followed with a larger study population. Both showed higher rates of recanalization and better 90-day clinical outcome in patients treated with IA r-proUK despite an increased incidence of early symptomatic intracranial hemorrhage. ${ }^{16,17}$ There was a trend towards better outcomes in secondary outcome measures. In spite of the encouraging results from this trial, r-proUK was never developed to the point of licensure for clinical use. The potential pitfalls of PROACT-II included use of heparin which may have contributed to increased major hemorrhage, inclusion of patients with irreversible changes on CT, lack of collateral assessment, and late treatment times. ${ }^{16,17}$

The EMS bridging trial was a small pilot $(n=35)$, prospective randomized trial that assessed the use of IV t-PA followed by IA t-PA vs. placebo followed by IA t-PA within 3 hours of stroke onset. The study showed that the combined IV-IA approach was safe and feasible in the first 3 hours. Despite having higher rates of recanalization, there was no evident benefit in the IV-IA therapy group compared to IA alone, due to the small sample size, and enrollment of more severe strokes in the IV-IA arm. ${ }^{18}$ The feasibility and safety of the IV-IA approach within 3 hours of acute ischemic stroke was further demonstrated in the IMS I \& IMS II studies. ${ }^{19,20}$ Both were prospective cohort studies in which the IA techniques were restricted to delivery of IA thrombolytic drug through microcatheters along with mechanical clot disruption by the guidewire or microcatheter.

The era of mechanical thrombectomy was launched with the development of Mechanical Embolus Removal in Cerebral Ischemia (MERCI) retriever. The rates of recanalization and chance of good clinical outcome were higher with the use of MERCI retriever when used with in 8 hours of stroke onset in the MERCI \& Multi MERCI trials. ${ }^{22,23}$ Although these were both cohort studies and not randomized clinical trials, the evidence was substantive enough to obtain FDA approval of MERCI retriever for mechanical thrombectomy in acute stroke. The Penumbra Stroke System, which works by debulking of thrombus with continuous aspiration was the next major development in the mechanical thrombectomy. ${ }^{24}$ The rates of recanalization in various series ranged from $67-82 \%$. Good clinical outcomes ( $\mathrm{mRS}<2$ ) occurred in 19-25\% and all-cause mortality ranged from $19-33 \% .{ }^{25-27}$ Following the introduction of MERCI and later development of Penumbra aspiration system, the focus of endovascular clinical trials shifted from use of IV-IA bridging thrombolysis to use of thrombolysis with bridging mechanical thrombectomy. Encouraging results in favor of IV-IA approach in the International Management of Stroke (IMS) I \& II studies and the results of MERCI \& Penumbra Stroke System trials led to the larger IMS III trial. ${ }^{21}$

In the IMS III trial, patients presenting with acute ischemic stroke within 3 hours and treated with IV t-PA were randomized to stop IV t-PA after 40 minutes of infusion and proceed to additional endovascular stroke therapy or to continue their IV t-PA infusion. Patients randomized to the endovascular arm were treated at the discretion of the interventionist using available techniques and devices as they were approved by regulatory authorities. At the time of trial initiation, IA t-PA and MERCI retriever were approved. Later on Penumbra aspiration system and Solitaire stent retriever were approved for use in the trial with protocol amendment's. The results of the IMS III trial were not encouraging, showing a similar efficacy and safety profile for both IV t-PA and endovascular approach.

The Intra-arterial Versus Systemic Thrombolysis for Acute Ischemic Stroke (SYNTHESIS EXP) trial compared outcomes between IV t-PA vs. IA therapy (IA t-PA and/or thrombus disruption) for acute stroke. In spite of having higher recanalization with IA therapy, there was no difference in the primary outcome of mRS of $0-1 .^{28}$ The Mechanical Retrieval and Recanalization of Stroke Clots Using Embolectomy (MR-RES- 
CUE) was a randomized clinical trial assessing the role of mechanical revascularization in acute stroke patients presenting beyond the standard IV t-PA treatment window based on ischemic pattern (penumbral vs. non penumbral) on multimodal imaging. ${ }^{29}$ Though the trial showed that neither the use of penumbral pattern for selecting treatment modality was useful nor embolectomy was superior to IV t-PA, there was a trend for a better 3-month outcome and lesser infarct growth in patients with adequate recanalization.

\section{Current Endovascular Stroke Trials}

The development of endovascular stroke therapies closely parallels the development of interventional cardiology. The evolution of treatment for acute ST elevation myocardial infarction started with use of nonspecific fibrinolytic drugs followed later by development of more specific fibrinolytic drugs and simultaneous development of percutaneous balloon angioplasty, bare metal coronary stents and then the drug eluting stents. Sequential randomized controlled trials have shown that achieving adequate and faster complete reperfusion [thrombolysis in myocardial infarction (TIMI) grade 3] are the single most important factors affecting the clinical outcome. ${ }^{30,31}$ TIMI 3 flow is achieved in only $50-60 \%$ of cases with the use of fibrinolytic drugs, and $90 \%$ with primary percutaneous coronary intervention (PCI). ${ }^{32-36}$ By comparison, the first trials or primary PCI were neutral or negative and it took several trials before it became clear that primary PCI was a superior treatment to medical thrombolytic therapy. Extrapolation of these finding to acute stroke management suggest that we need to achieve these same fast and complete reperfusion rates to see success. This is now possible with the current generation of mechanical thrombectomy devices.

Success in the current endovascular stroke trials in our view is dependent upon four factors. These are: 1) consecutive enrolment of trial-eligible patients; 2) careful selection of patients using fast stroke imaging; 3) very fast treatment; 4) $90 \%$ or better reperfusion of the target circulation (Fig. 1).

\section{Consecutive Enrollment}

Commitment to enrolling patients into a clinical trial is critical to both success and generalizability after the fact. If only some of all eligible patients are enrolled the external validity of the study results are threatened. Both MR-RESCUE and IMS III took many years to recruit in part because eligible patients were being treated in clinical routine rather than being enrolled and randomized. This delay in completion allowed ongoing technological development, which left the study design behind. The populations studied may have been the least likely to benefit from the interventional therapy. There is no practical way to enforce consecutive enrolment at a given clinical cen-

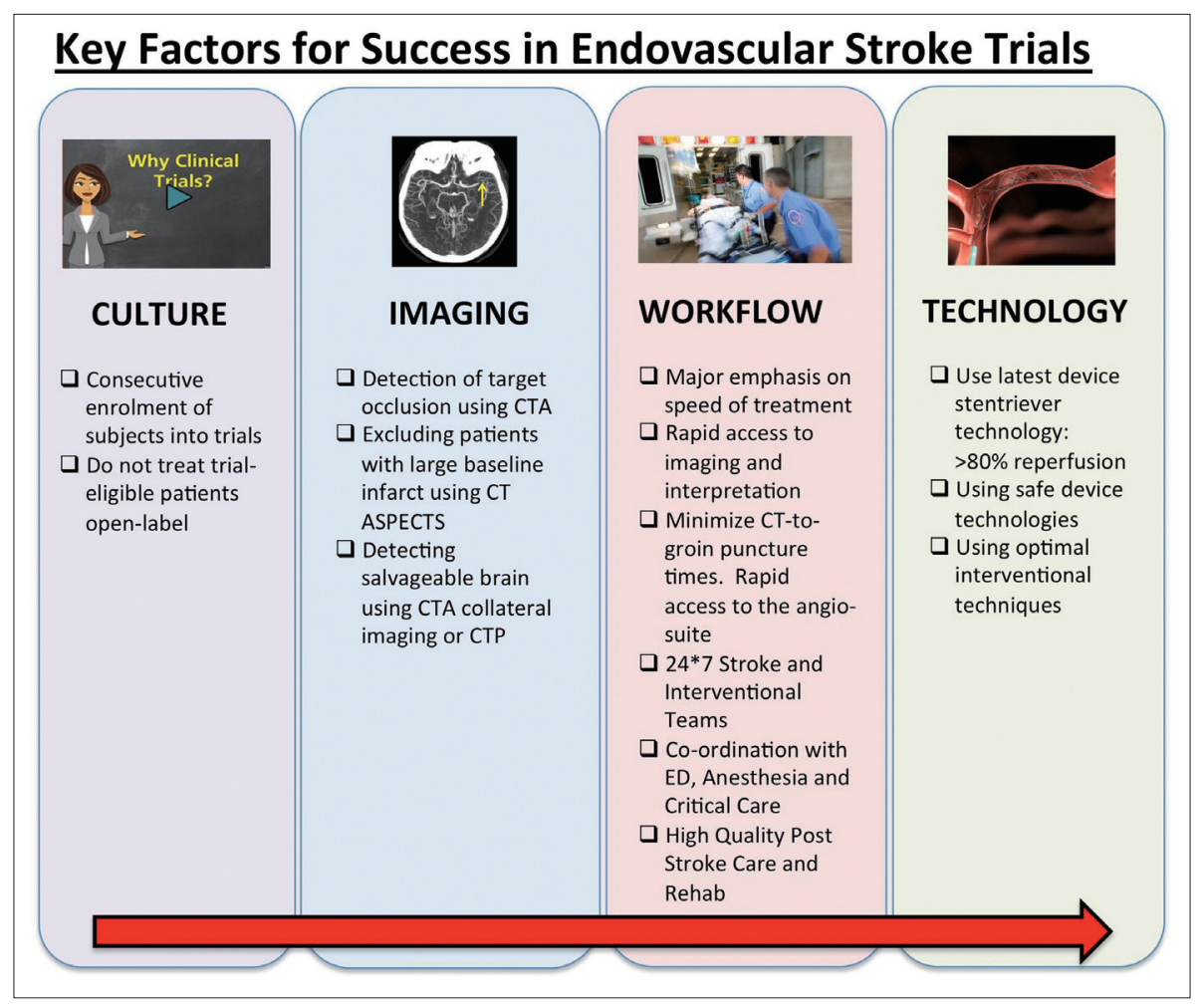

Fig. 1. Key factors for success in endovascular stroke trials. 
tre; instead the commitment is matter of clinical academic rigour and a handshake agreement.

\section{Selection Based on Imaging}

The importance of imaging based selection is supported by the accumulating evidence of the role of collaterals, baseline ischemic core size in affecting clinical outcomes, and vascular imaging in identifying patients with target lesions that maximally benefit form endovascular therapy..$^{37-44}$

Early ischemic changes seen as hypodensity or loss of grey white differentiation indicate irreversible parenchymal damage. ${ }^{45}$ Identification and quantification of the ischemic core, the tissue that is dead or destined to die, is important for predicting the outcome. ${ }^{3}$ If a significant core of ischemic tissue is present on initial imaging, the outcome of the patient will be poor despite aggressive therapy. ${ }^{46,47}$ Reperfusion in a patient with significant ischemic core is doubly unhelpful. First, the dead infarct cannot be helped by reperfusion and second, reperfusion increases the chance of spontaneous intracranial hemorrhage (SICH) ${ }^{48}$

Quantification of the ischemic core can be based upon either brain MRI or CT. The MRI DWI lesion volume is the most precise estimate of the infarct core. However, there are several practical limitations to the use of MR in acute stroke. ${ }^{49}$ Quantification of the early ischemic changes on the images of the CT head may be done using the Alberta Stroke Program Early CT Score (ASPECTS) score. A pretreatment ASPECTS $>7$ is associated with a reduced risk of SICH in acute stroke treated with IV t-PA..$^{50}$ Earlier trials of endovascular therapy have not adequately assessed the extent of early ischemic changes on the initial CT scan for selecting the patient into the trial. Analysis of PROACT II and IMS I data and more recently the IMS III trial has shown that using ASPECTS may help to choose ideal patients for endovascular therapy. ${ }^{51} \mathrm{~Pa}-$ tients with an ASPECTS score of 8-10 were more likely to have good outcomes compared to patients with an ASPECT of 0-7 in the IMS III trial. Moreover patients with ASPECTS score of 8-10 were more likely to have a recanalization of the primary arterial occlusive lesion and more likely to have thrombolysis in cerebral ischemia (TICI) $2 \mathrm{~b}$ or 3 grade reperfusion. $^{51,52}$

The ischemic core and penumbra may be quantified using perfusion imaging with CT or MRI. The importance of early reperfusion in improving the clinical outcome in patients with perfusion-diffusion mismatch on MR was demonstrated in the diffusion and perfusion imaging evaluation for understanding stroke evolution (DEFUSE) and Echoplanar Imaging Thrombolytic Evaluation Trial study. ${ }^{40,41}$ In the DEFUSE 2 study, it was observed that the patients with mismatch ben- efited from reperfusion irrespective of the time from symptom onset. ${ }^{42}$ In these studies, it was clearly demonstrated that patients with large DWI lesions and no mismatch i.e., a large ischemic core not only had poor clinical response despite recanalization, but also had higher risk of symptomatic intracerebral hemorrhage. ${ }^{40-42}$ The size of the baseline DWI \& perfusion-weighted imaging lesion predicts the chance of a good clinical outcome irrespective of the recanalization status. ${ }^{53,54}$ Though perfusion imaging can be used to select patients for thrombolytic therapy as well as prognosticate the clinical outcome and risk of hemorrhagic transformation, the utility is hampered by the lack of consensus on the perfusion parameter to be used, the amount of mismatch and post processing techniques. ${ }^{37-39,55-58}$

Stroke is primarily a disease of the vasculature. Vascular imaging helps in determining the severity and extent of occlusion and the collateral status and in an immediate understanding of the physiology of the stroke. ${ }^{59,60}$ The identification of the arterial occlusion helps in predicting the response to the thrombolytic therapy as well as guiding the judicious use of endovascular therapy. ${ }^{6}$ Baseline ischemic changes are significantly influenced by leptomeningeal collateral status. Collaterals play an important role in the outcome of a stroke patient and influence the clinical deficit, the brain tolerance to ischemia and the time window available for the urgent stroke revascularization. Analysis of the recent endovascular stroke trials has shown that patients with good collaterals have better baseline and 24-hour ASPECTS score, higher rates of recanalization, reperfusion and good clinical outcomes. ${ }^{61-64}$ This supports the utility of collateral assessment in selecting the patients for endovascular therapy. ${ }^{65}$

In the IMS III, baseline ASPECTS was not mandatory before enrolling study participants, however patients with significant baseline ischemia on CT i.e., more than 1/3rd MCA territory were excluded. 92 of the 656 patients enrolled in IMS III had a baseline ASPECTS of 0-4 indicating severe baseline ischemia and 57 of these were in the endovascular arm..$^{51}$ Only $6 \%$ and $15 \%$ of the subjects with a baseline ASPECTS of $0-4$ had achieved a mRS of $0-1$ and $0-2$, respectively. Similarly, baseline vascular imaging was not required to be done per protocol, but 305 of the 656 patients enrolled in the IMS III trial had a baseline CT angiography (CTA) as per local stroke practice. Of these 305 patients, 24 showed no occlusion and of these 21 were randomized to the endovascular arm. 80 of the patients in the endovascular arm did not have a target occlusive lesion. A total of 147 patients in the IMS III cohort did not have a target arterial occlusive lesion responsible for the stroke. ${ }^{66}$

In the MR-RESCUE study, though base line penumbral imaging was done it was not used to select patients for endovas- 
cular therapy in the study. Vascular imaging was however used to select patients with a large vessel occlusion (ICA, M1 MCA, M2 MCA) and only 5 of the $70(7 \%)$ patients randomized to the endovascular therapy did not have a MR-demonstrable occlusion. ${ }^{67}$ In the SYNTHESIS EXP study, neither the baseline quantification of the ischemic imaging nor vascular imaging to identify the target occlusive lesion or collaterals was used as entry criteria for the study participants. ${ }^{28}$ However, only 3 of the 181 patients in the endovascular arm however did not have any occlusion observed at angiography.

\section{Faster Reperfusion}

Faster treatment from stroke onset to intravenous t-PA is associated with better clinical outcome. ${ }^{68,69}$ The same is true for endovascular therapy: in all the major endovascular trials to date, it has been convincingly demonstrated that the longer time to initiation of treatment resulted in a worse clinical outcome. ${ }^{17,19,20,22-24,70}$ In the IMS III trial, the time to reperfusion was associated with a decreasing chance of good clinical outcome and increased risk of adverse events seen with delayed reperfusion. There is a $12-15 \%$ relative reduction in likelihood of a good clinical outcome for every 30-minute delay in the time to reperfusion. ${ }^{71}$ The mean time from onset to groin puncture and the onset to IA therapy time in the IMS III was 208 and 249.4 minutes respectively indicating significant delay in the treatment. In the cohort of patients who achieved reperfusion, the mean time from symptom onset to reperfusion was 325 minutes with significant delay attributable to IV t-PA to groin puncture and groin puncture to reperfusion of 81 and 124 minutes respectively. ${ }^{71}$ The mean time from symptom onset to endovascular therapy in the MR-RESCUE study was 381 min. ${ }^{67}$ In SYNTHESIS EXP, the median time from symptom onset to start of endovascular therapy was 225 minutes in the endovascular therapy group. ${ }^{28}$ The importance and feasibility of faster endovascular recanalization treatments in improving the clinical outcome is further highlighted in the Solitaire FR Thrombectomy for Acute Revascularization study. ${ }^{72}$ Door to needle times as fast as 20-25 minutes can be achieved with proper planning and infrastructure changes. ${ }^{73,74}$ Strict adherence to stroke performance metrics like door to needle time, picture-to-puncture, picture-to-perfusion time and comprehensive metrics like symptom onset to reperfusion time can vastly improve the chances of good clinical outcome. ${ }^{75-78}$ Measures targeting overall system improvement focusing on faster transport, faster transfer of the clinical data, rapid imaging \& mobilization of the interventional team will lead to faster reperfusion and thus improve the overall clinical outcome. ${ }^{72,78,79}$

\section{0\% Reperfusion}

The ultimate aim of endovascular stroke therapy is to reperfuse the ischemic brain, which in turn is a critical determinant of the good clinical outcome. The adequacy of reperfusion is measured by using TICI score on an angiography or a CT angiography. ${ }^{80}$ There is a graded relationship between the degree of reperfusion and outcome. Whereas, prior simple dichotomization of the TICI at 0 or 1 vs. 2 or 3 (based upon the same approach in coronary artery disease with the TIMI score), was the standard of reporting, it is now clear that a TICI score of $2 b$ or 3 is required for a good angiographic outcome; TICI $2 \mathrm{a}$ is not enough.

Reporting of reperfusion has been variable among prior studies. Among patients with complete proximal occlusions in the anterior circulation treated with endovascular therapy in the IMS III study, $40 \%$ of the patients achieving TICI 2 or 3 reperfusion had good clinical outcome vs. $10 \%$ of patients with out reperfusion. ${ }^{71}$ The rates of TICI $2 \mathrm{~b}$ or 3 recanalization in the IMS III was 38\% for an internal carotid occlusion, $44 \%$ for an M1 occlusion, 44\% for a single M2 occlusion, 23\% for multiple M2 occlusions. The rates of TIMI 2 or 3 recanalization with the Penumbra Aspiration system were $82 \%$ in the Penumbra pivotal stroke trial. ${ }^{24}$ In the POST trial, a post marketing study, the rates of TIMI 2 or 3 recanalization with Penumbra system were $87 \% .{ }^{81}$ In the SWIFT study, the rates of early reperfusion of TIMI grade 2 or 3 were $69 \%$ with the Solitaire device and 30\% with the MERCI retriever. In the Trevo versus Merci retrievers for thrombectomy revascularisation of large vessel occlusions in acute ischaemic stroke (TREVO 2) study, the rate of TICI 2 or 3 recanalization was $86 \%$ with the TREVO stent retriever and $60 \%$ with the MERCI retriever. The rates of TICI $2 \mathrm{~b}$ or 3 recanalization with TREVO and MERCI retriever's were $68 \%$ and $44 \%$, respectively. The overall rate of TICI 2 or 3 recanalization in the endovascular arm of the IMS III was $41.9 \%(182 / 434)$. The rates of TICI 2 or 3 recanalization in the IMS III with individual devices is as follows $-73 \%$ with the Merci Retriever, $85 \%$ with the Penumbra system, 75\% with the Solitaire device. In the MR-RESCUE tri$\mathrm{al}$, the rates of post procedure recanalization (TICI $2 \mathrm{~b}$ or 3 ) was just $27 \%$ (supplementary data). ${ }^{67}$ The rates of post procedure recanalization were not available from the SYNTHESIS EXP study. ${ }^{28}$ No study has yet achieved a $90 \%$ good reperfusion (TICI $2 \mathrm{~b}$ or 3 ) target, which we argue is the most meaningful reperfusion metric.

Recanalization and reperfusion are two independent measures of therapeutic efficacy and the timing of measurement of the former has implications in assessing the treatment outcome. In the IMS III trial all patients had a 24-hour CTA to assess recanalization. ${ }^{21}$ Measuring the recanalization after a con- 
siderable delay from the initial treatment will not be able to differentiate between those with early vs. late recanalization by including patients with delayed spontaneous recanalization. There is often a mismatch in the clinical trials with higher reperfusion rates but lesser rates of good clinical outcomes. This is referred to as futile recanalization. The rates of futile recanalization have ranged form $30 \%$ to $50 \%$ in various endovascular trials. ${ }^{16,20,82}$ The apparent higher rates of futile recanalization in earlier endovascular stroke trials are, in part due to the timing of measurement. This was evident in IMS-III where 24-hour CTA-defined recanalization rate was approximately double the rate immediately post-angiography. Thus, reasons for poor outcomes after endovascular stroke therapy include not only lack of recanalization but also late (or futile) recanalization.

\section{The Way Ahead for Endovascular Stroke Treatment}

Endovascular stroke therapy is at a cross-roads. There are multiple ongoing clinical trials. We believe that success will be determined by whether trials can execute on all four of these pillars of treatment described above. This is a major focus of the ESCAPE trial [NCT01778335]. Other ongoing trials have taken differing approaches, not making all four of these factors so critical in deciding who to treat. It is an exciting time to be involved in stroke treatment because patients with an otherwise fatal illness can be cured and walk out of hospital. Our understanding of baseline imaging is going to be finally defined by outcomes because our results will no longer be confounded by lack of reperfusion.

Completion of the current endovascular trials with positive results is going to result in necessary changes in the structure of stroke care. We predict that there will be a center-by-volume relationships with outcomes because high performing teams will have the best treatment times and the best outcomes. We predict that centralization of stroke care will benefit not only those who are candidates for endovascular treatment but all stroke patients who get diverted to central stroke units.

For now, we must focus our efforts on very high performance in clinical research studies and we must execute endovascular treatment interventions very fast with high reperfusion rates.

\section{Conflicts of Interest}

The authors have no financial conflicts of interest.

\section{Acknowledgements}

The ESCAPE trials is funded by a consortium from Covidien, Heart \& Stroke Foundation Alberta, Alberta Innovates Health Solutions, Hotch- kiss Brain Institute, Department of Clinical Neurosciences, Department of Radiology, Calgary Stroke Program.

\section{REFERENCES}

1. Natarajan SK, Eller JL, Snyder KV, Hopkins LN, Levy EI, Siddiqui AH. Endovascular treatment of acute ischemic stroke. Neuroimaging Clin N Am 2013;23:673-694.

2. Heiss WD, Rosner G. Functional recovery of cortical neurons as related to degree and duration of ischemia. Ann Neurol 1983;14:294-301.

3. Tissue plasminogen activator for acute ischemic stroke. The National Institute of Neurological Disorders and Stroke rt-PA Stroke Study Group. N Engl J Med 1995;333:1581-1587.

4. Bivard A, Lin L, Parsonsb MW. Review of stroke thrombolytics. $J$ Stroke 2013;15:90-98.

5. Grunwald IQ, Wakhloo AK, Walter S, Molyneux AJ, Byrne JV, Nagel $\mathrm{S}$, et al. Endovascular stroke treatment today. AJNR Am J Neuroradiol 2011;32:238-243.

6. Mishra SM, Dykeman J, Sajobi TT, Trivedi A, Almekhlafi M, Sohn SI, et al. Early Reperfusion Rates with IV tPA Are Determined by CTA Clot Characteristics. AJNR Am J Neuroradiol 2014;35:2265-2272.

7. Saqqur M, Uchino K, Demchuk AM, Molina CA, Garami Z, Calleja $\mathrm{S}$, et al. Site of arterial occlusion identified by transcranial Doppler predicts the response to intravenous thrombolysis for stroke. Stroke 2007;38:948-954.

8. del Zoppo GJ, Poeck K, Pessin MS, Wolpert SM, Furlan AJ, Ferbert A, et al. Recombinant tissue plasminogen activator in acute thrombotic and embolic stroke. Ann Neurol 1992;32:78-86.

9. Bhatia R, Shobha N, Menon BK, Bal SP, Kochar P, Palumbo V, et al. Combined full-dose IV and endovascular thrombolysis in acute ischaemic stroke. Int J Stroke 2014;9:974-979.

10. Sussman BJ, Fitch TS. Thrombolysis with fibrinolysin in cerebral arterial occlusion. J Am Med Assoc 1958;167:1705-1709.

11. del Zoppo GJ, Ferbert A, Otis S, Brückmann H, Hacke W, Zyroff J, et al. Local intra-arterial fibrinolytic therapy in acute carotid territory stroke. A pilot study. Stroke 1988;19:307-313.

12. Hacke W, Zeumer H, Ferbert A, Brückmann H, del Zoppo GJ. Intraarterial thrombolytic therapy improves outcome in patients with acute vertebrobasilar occlusive disease. Stroke 1988;19:1216-1222.

13. Mori E, Tabuchi M, Yoshida T, Yamadori A. Intracarotid urokinase with thromboembolic occlusion of the middle cerebral artery. Stroke 1988;19:802-812.

14. del Zoppo GJ, Pessin MS, Mori E, Hacke W. Thrombolytic intervention in acute thrombotic and embolic stroke. Semin Neurol 1991;11: 368-384.

15. Zeumer H, Freitag HJ, Zanella F, Thie A, Arning C. Local intra-arterial fibrinolytic therapy in patients with stroke: urokinase versus recombinant tissue plasminogen activator (r-TPA). Neuroradiology 1993;35: 159-162.

16. del Zoppo GJ, Higashida RT, Furlan AJ, Pessin MS, Rowley HA, Gent M. PROACT: a phase II randomized trial of recombinant prourokinase by direct arterial delivery in acute middle cerebral artery stroke. PROACT Investigators. Prolyse in Acute Cerebral Thromboembolism. Stroke 1998;29:4-11.

17. Furlan A, Higashida R, Wechsler L, Gent M, Rowley H, Kase C, et al. Intra-arterial prourokinase for acute ischemic stroke. The PROACT II study: a randomized controlled trial. Prolyse in Acute Cerebral Thromboembolism. JAMA 1999;282:2003-2011.

18. Lewandowski CA, Frankel M, Tomsick TA, Broderick J, Frey J, Clark W, et al. Combined intravenous and intra-arterial r-TPA versus intra-arterial therapy of acute ischemic stroke: Emergency Management of Stroke (EMS) Bridging Trial. Stroke 1999;30:2598-2605.

19. IMS Study Investigators. Combined intravenous and intra-arterial recanalization for acute ischemic stroke: the Interventional Management of Stroke Study. Stroke 2004;35:904-911. 
20. IMS II Trial Investigators. The Interventional Management of Stroke (IMS) II Study. Stroke 2007;38:2127-2135.

21. Broderick JP, Palesch YY, Demchuk AM, Yeatts SD, Khatri P, Hill $\mathrm{MD}$, et al. Endovascular therapy after intravenous t-PA versus t-PA alone for stroke. N Engl J Med 2013;368:893-903.

22. Smith WS, Sung G, Starkman S, Saver JL, Kidwell CS, Gobin YP, et al. Safety and efficacy of mechanical embolectomy in acute ischemic stroke: results of the MERCI trial. Stroke 2005;36:1432-1438.

23. Smith WS, Sung G, Saver J, Budzik R, Duckwiler G, Liebeskind DS, et al. Mechanical thrombectomy for acute ischemic stroke: final results of the Multi MERCI trial. Stroke 2008;39:1205-1212.

24. Penumbra Pivotal Stroke Trial Investigators. The penumbra pivotal stroke trial: safety and effectiveness of a new generation of mechanical devices for clot removal in intracranial large vessel occlusive disease. Stroke 2009;40:2761-2768.

25. Struffert T, Köhrmann M, Engelhorn T, Nowe T, Richter G, Schellinger PD, et al. Penumbra Stroke System as an "add-on" for the treatment of large vessel occlusive disease following thrombolysis: first results. Eur Radiol 2009;19:2286-2293.

26. Menon BK, Hill MD, Eesa M, Modi J, Bhatia R, Wong J, et al. Initial experience with the Penumbra Stroke System for recanalization of large vessel occlusions in acute ischemic stroke. Neuroradiology 2011; 53:261-266.

27. Kulcsár Z, Bonvin C, Pereira VM, Altrichter S, Yilmaz H, Lövblad $\mathrm{KO}$, et al. Penumbra system: a novel mechanical thrombectomy device for large-vessel occlusions in acute stroke. AJNR Am J Neuroradiol 2010;31:628-633.

28. Ciccone A, Valvassori L, Nichelatti M, Sgoifo A, Ponzio M, Sterzi R, et al. Endovascular treatment for acute ischemic stroke. $N$ Engl $J$ Med 2013;368:904-913.

29. Kidwell CS, Jahan R, Alger JR, Schaewe TJ, Guzy J, Starkman S, et al. Design and rationale of the Mechanical Retrieval and Recanalization of Stroke Clots Using Embolectomy (MR RESCUE) Trial. Int $J$ Stroke 2014;9:110-116.

30. Holmes DR Jr, Califf RM, Topol EJ. Lessons we have learned from the GUSTO trial. Global Utilization of Streptokinase and Tissue Plasminogen Activator for Occluded Arteries. J Am Coll Cardiol 1995; 25(7 Suppl):10S-17S.

31. Gibson CM, Murphy SA, Marble SJ, McCabe CH, Antman EM, Cannon $\mathrm{CP}$, et al. Can we replace the 90 -minute thrombolysis in myocardial infarction (TIMI) flow grades with those at 60 minutes as a primary end point in thrombolytic trials? TIMI Study Group. Am J Cardiol 2001;87:450-453, A6.

32. The effects of tissue plasminogen activator, streptokinase, or both on coronary-artery patency, ventricular function, and survival after acute myocardial infarction. The GUSTO Angiographic Investigators. $N$ Engl J Med 1993;329:1615-1622.

33. Stone GW, Grines CL, Cox DA, Garcia E, Tcheng JE, Griffin JJ, et al. Comparison of angioplasty with stenting, with or without abciximab, in acute myocardial infarction. N Engl J Med 2002;346:957-966.

34. Mehta RH, Harjai KJ, Cox D, Stone GW, Brodie B, Boura J, et al. Clinical and angiographic correlates and outcomes of suboptimal coronary flow inpatients with acute myocardial infarction undergoing primary percutaneous coronary intervention. J Am Coll Cardiol 2003;42: 1739-1746

35. Anderson JL, Karagounis LA, Califf RM. Metaanalysis of five reported studies on the relation of early coronary patency grades with mortality and outcomes after acute myocardial infarction. Am J Cardiol 1996;78:1-8.

36. An international randomized trial comparing four thrombolytic strategies for acute myocardial infarction. The GUSTO investigators. $N$ Engl J Med 1993;329:673-682.

37. Takasawa M, Jones PS, Guadagno JV, Christensen S, Fryer TD, Harding $\mathrm{S}$, et al. How reliable is perfusion MR in acute stroke? Validation and determination of the penumbra threshold against quantitative PET.
Stroke 2008;39:870-877.

38. Fiorella D, Heiserman J, Prenger E, Partovi S. Assessment of the reproducibility of postprocessing dynamic CT perfusion data. AJNR Am J Neuroradiol 2004;25:97-107.

39. Latchaw RE, Alberts MJ, Lev MH, Connors JJ, Harbaugh RE, Higashida RT, et al. Recommendations for imaging of acute ischemic stroke: a scientific statement from the American Heart Association. Stroke 2009;40:3646-3678.

40. Albers GW, Thijs VN, Wechsler L, Kemp S, Schlaug G, Skalabrin E, et al. Magnetic resonance imaging profiles predict clinical response to early reperfusion: the diffusion and perfusion imaging evaluation for understanding stroke evolution (DEFUSE) study. Ann Neurol 2006;60: 508-517.

41. Davis SM, Donnan GA, Parsons MW, Levi C, Butcher KS, Peeters A, et al. Effects of alteplase beyond $3 \mathrm{~h}$ after stroke in the Echoplanar Imaging Thrombolytic Evaluation Trial (EPITHET): a placebo-controlled randomised trial. Lancet Neurol 2008;7:299-309.

42. Lansberg MG, Straka M, Kemp S, Mlynash M, Wechsler LR, Jovin TG, et al. MRI profile and response to endovascular reperfusion after stroke (DEFUSE 2): a prospective cohort study. Lancet Neurol 2012; 11:860-867.

43. Turk AS, Magarick JA, Frei D, Fargen KM, Chaudry I, Holmstedt $\mathrm{CA}$, et al. CT perfusion-guided patient selection for endovascular recanalization in acute ischemic stroke: a multicenter study. J Neurointerv Surg 2013;5:523-527.

44. Nguyen TN, Zaidat OO, Edgell RC, Janjua N, Yavagal DR, Xavier $\mathrm{AR}$, et al. Vascular neurologists and neurointerventionalists on endovascular stroke care: polling results. Neurology 2012;79(13 Suppl 1): S5-S15.

45. von Kummer R, Allen KL, Holle R, Bozzao L, Bastianello S, Manelfe $\mathrm{C}$, et al. Acute stroke: usefulness of early CT findings before thrombolytic therapy. Radiology 1997;205:327-333.

46. Yoo AJ, Zaidat OO, Chaudhry ZA, Berkhemer OA, González RG, Goyal M, et al. Impact of pretreatment noncontrast CT Alberta Stroke Program Early CT Score on clinical outcome after intra-arterial stroke therapy. Stroke 2014;45:746-751.

47. Menon BK, Puetz V, Kochar P, Demchuk AM. ASPECTS and other neuroimaging scores in the triage and prediction of outcome in acute stroke patients. Neuroimaging Clin N Am 2011;21:407-423, xii.

48. Mlynash M, Lansberg MG, De Silva DA, Lee J, Christensen S, Straka $\mathrm{M}$, et al. Refining the definition of the malignant profile: insights from the DEFUSE-EPITHET pooled data set. Stroke 2011;42:1270-1275.

49. Fiebach JB, Schellinger PD, Jansen O, Meyer M, Wilde P, Bender J, et al. CT and diffusion-weighted MR imaging in randomized order: diffusion-weighted imaging results in higher accuracy and lower interrater variability in the diagnosis of hyperacute ischemic stroke. Stroke 2002;33:2206-2210.

50. Barber PA, Demchuk AM, Zhang J, Buchan AM. Validity and reliability of a quantitative computed tomography score in predicting outcome of hyperacute stroke before thrombolytic therapy. ASPECTS Study Group. Alberta Stroke Programme Early CT Score. Lancet 2000;355:1670-1674.

51. Hill MD, Demchuk AM, Goyal M, Jovin TG, Foster LD, Tomsick TA, et al. Alberta Stroke Program early computed tomography score to select patients for endovascular treatment: Interventional Management of Stroke (IMS)-III Trial. Stroke 2014;45:444-449.

52. Liebeskind DS, Jahan R, Nogueira RG, Zaidat OO, Saver JL; SWIFT Investigators. Impact of collaterals on successful revascularization in Solitaire FR with the intention for thrombectomy. Stroke 2014;45: 2036-2040.

53. Yoo AJ, Verduzco LA, Schaefer PW, Hirsch JA, Rabinov JD, González RG. MRI-based selection for intra-arterial stroke therapy: value of pretreatment diffusion-weighted imaging lesion volume in selecting patients with acute stroke who will benefit from early recanalization. Stroke 2009;40:2046-2054. 
54. Parsons MW, Christensen S, McElduff P, Levi CR, Butcher KS, De Silva DA, et al. Pretreatment diffusion- and perfusion-MR lesion volumes have a crucial influence on clinical response to stroke thrombolysis. J Cereb Blood Flow Metab 2010;30:1214-1225.

55. Fisher M. Is penumbral imaging useful for extending the treatment window for intravenous tissue plasminogen activator? Ann Neurol 2006;60:499-501.

56. Yoo AJ, Pulli B, Gonzalez RG. Imaging-based treatment selection for intravenous and intra-arterial stroke therapies: a comprehensive review. Expert Rev Cardiovasc Ther 2011;9:857-876.

57. Kane I, Sandercock P, Wardlaw J. Magnetic resonance perfusion diffusion mismatch and thrombolysis in acute ischaemic stroke: a systematic review of the evidence to date. J Neurol Neurosurg Psychiatry 2007;78:485-491.

58. Butcher KS, Parsons M, MacGregor L, Barber PA, Chalk J, Bladin C, et al. Refining the perfusion-diffusion mismatch hypothesis. Stroke 2005;36:1153-1159.

59. Menon BK, O’Brien B, Bivard A, Spratt NJ, Demchuk AM, Miteff F, et al. Assessment of leptomeningeal collaterals using dynamic CT angiography in patients with acute ischemic stroke. J Cereb Blood Flow Metab 2013;33:365-371.

60. Menon BK, Demchuk AM. Computed Tomography Angiography in the Assessment of Patients With Stroke/TIA. Neurohospitalist 2011;1: 187-199.

61. Nogueira RG, Lutsep HL, Gupta R, Jovin TG, Albers GW, Walker GA, et al. Trevo versus Merci retrievers for thrombectomy revascularisation of large vessel occlusions in acute ischaemic stroke (TREVO 2): a randomised trial. Lancet 2012;380:1231-1240.

62. Saver JL, Jahan R, Levy EI, Jovin TG, Baxter B, Nogueira RG, et al. Solitaire flow restoration device versus the Merci Retriever in patients with acute ischaemic stroke (SWIFT): a randomised, parallel-group, non-inferiority trial. Lancet 2012;380:1241-1249.

63. Liebeskind DS, Tomsick TA, Foster LD, Yeatts SD, Carrozzella J, Demchuk AM, et al. Collaterals at angiography and outcomes in the Interventional Management of Stroke (IMS) III trial. Stroke 2014;45: 759-764.

64. Liebeskind DS. Trials of endovascular therapies or collaterals? Int $J$ Stroke 2013;8:258-259.

65. Nambiar V, Sohn SI, Almekhlafi MA, Chang HW, Mishra S, Qazi E, et al. CTA collateral status and response to recanalization in patients with acute ischemic stroke. AJNR Am J Neuroradiol 2014;35:884890.

66. Demchuk AM, Goyal M, Yeatts SD, Carrozzella J, Foster LD, Qazi E, et al. Recanalization and clinical outcome of occlusion sites at baseline CT angiography in the Interventional Management of Stroke III trial. Radiology 2014;273:202-210.

67. Kidwell CS, Jahan R, Gornbein J, Alger JR, Nenov V, Ajani Z, et al. A trial of imaging selection and endovascular treatment for ischemic stroke. N Engl J Med 2013;368:914-923.

68. Lees KR, Bluhmki E, von Kummer R, Brott TG, Toni D, Grotta JC, et al. Time to treatment with intravenous alteplase and outcome in stroke: an updated pooled analysis of ECASS, ATLANTIS, NINDS, and EPITHET trials. Lancet 2010;375:1695-1703.
69. Marler JR, Tilley BC, Lu M, Brott TG, Lyden PC, Grotta JC, et al. Early stroke treatment associated with better outcome: the NINDS rtPA stroke study. Neurology 2000;55:1649-1655.

70. Alexandrov AV, Molina CA, Grotta JC, Garami Z, Ford SR, AlvarezSabin J, et al. Ultrasound-enhanced systemic thrombolysis for acute ischemic stroke. N Engl J Med 2004;351:2170-2178.

71. Khatri P, Yeatts SD, Mazighi M, Broderick JP, Liebeskind DS, Demchuk AM, et al. Time to angiographic reperfusion and clinical outcome after acute ischaemic stroke: an analysis of data from the Interventional Management of Stroke (IMS III) phase 3 trial. Lancet Neurol 2014;13:567-574.

72. Menon BK, Almekhlafi MA, Pereira VM, Gralla J, Bonafe A, Davalos A, et al. Optimal workflow and process-based performance measures for endovascular therapy in acute ischemic stroke: analysis of the Solitaire FR thrombectomy for acute revascularization study. Stroke 2014;45:2024-2029.

73. Meretoja A, Weir L, Ugalde M, Yassi N, Yan B, Hand P, et al. Helsinki model cut stroke thrombolysis delays to 25 minutes in Melbourne in only 4 months. Neurology 2013;81:1071-1076.

74. Meretoja A, Strbian D, Mustanoja S, Tatlisumak T, Lindsberg PJ, Kaste M. Reducing in-hospital delay to 20 minutes in stroke thrombolysis. Neurology 2012;79:306-313.

75. Khatri P, Abruzzo T, Yeatts SD, Nichols C, Broderick JP, Tomsick TA, et al. Good clinical outcome after ischemic stroke with successful revascularization is time-dependent. Neurology 2009;73:1066-1072.

76. Sun CH, Nogueira RG, Glenn BA, Connelly K, Zimmermann S, Anda K, et al. "Picture to puncture": a novel time metric to enhance outcomes in patients transferred for endovascular reperfusion in acute ischemic stroke. Circulation 2013;127:1139-1148.

77. Gupta R, Horev A, Nguyen T, Gandhi D, Wisco D, Glenn BA, et al. Higher volume endovascular stroke centers have faster times to treatment, higher reperfusion rates and higher rates of good clinical outcomes. J Neurointerv Surg 2013;5:294-297.

78. Sun CH, Bhatt DL, Nogueira RG, Gupta R. Endovascular therapy for stroke: getting to the "heart" of the matter. Circulation 2014;129:11521160.

79. Almekhlafi MA, Hockley A, Desai JA, Nambiar V, Mishra S, Volny $\mathrm{O}$, et al. Overcoming the evening/weekend effects on time delays and outcomes of endovascular stroke therapy: the Calgary Stroke Program experience. J Neurointerv Surg 2014;6:729-732.

80. Tomsick T. TIMI, TIBI, TICI: I came, I saw, I got confused. AJNR Am J Neuroradiol 2007;28:382-384.

81. Tarr R, Hsu D, Kulcsar Z, Bonvin C, Rufenacht D, Alfke K, et al. The POST trial: initial post-market experience of the Penumbra system: revascularization of large vessel occlusion in acute ischemic stroke in the United States and Europe. J Neurointerv Surg 2010;2:341-344.

82. Shi ZS, Loh Y, Walker G, Duckwiler GR; MERCI and Multi-MERCI Investigators. Clinical outcomes in middle cerebral artery trunk occlusions versus secondary division occlusions after mechanical thrombectomy: pooled analysis of the Mechanical Embolus Removal in Cerebral Ischemia (MERCI) and Multi MERCI trials. Stroke 2010;41: 953-960. 